\title{
Fatal familial insomnia: clinical, neuropathological, and genetic description of a Spanish family
}

\author{
C Tabernero, J M Polo, M D Sevillano, R Muñoz, J Berciano, A Cabello, B Báez,
} J R Ricoy, R Carpizo, J Figols, N Cuadrado, L E Claveria

Neurology Section, Hospital General de Segovia, ctra de Ávila sn, 40001 Segovia, Spain

C Tabernero

M D Sevillano

L E Claveria

Neurology Service, University Hospital

"Marqués de

Valdecilla", Santander,

Spain

$\mathrm{J}$ M Polo

R Muñoz

J Berciano

Neuropathology

Section, University

Hospital " $12^{\circ} \mathrm{de}$

Octubre", Madrid,

Spain

A Cabello

B Báez

J R Ricoy

Clinical

Neurophysiology

Service, University

Hospital "Marqués de

Valdecilla", Santander,

Spain

R Carpizo

Pathology Service, University Hospital "Marqués de

Valdecilla", Santander,

Spain

J Figols

Health Institute "Carlos III", Madrid, Spain

N Cuadrado

Correspondence to: Dr César Tabernero ctabernerog@meditex.es

Received 13 August 1999 and in final form

3 February 2000

Accepted 9 February 2000

\begin{abstract}
The clinical presentation and evolution, neuropathological findings, and genotyping of three members of a Spanish family affected with fatal familial insomnia are reported. The mother and two of her offspring developed a rapidly evolving disease with insomnia and behavioural disorders as the initial symptoms and died between 5 and 10 months after the onset of the illness. Frontal brain biopsy in the mother disclosed only non-significant spongiosis, and full neuropathological examination of her offspring showed thalamic and olivary degeneration with isolated focal cortical spongiosis. Genetic examination could only be performed in the contemporary patients and both harboured the prion protein (PrP) 178Asn mutation and homozygous $129 \mathrm{Met} / \mathrm{Met}$ genotype.
\end{abstract}

(F Neurol Neurosurg Psychiatry 2000;68:774-777)

Keywords: prion diseases; thalamus; sleep disorders

Fatal familial insomnia is an autosomal dominant disease characterised by severe untreatable insomnia, autonomic disturbances, peculiar cognitive disorder, motor system deficits, and endocrine manifestations. ${ }^{1}$ The cognitive disorder, especially in first stages, is an attentional disturbance ${ }^{2}$ with short term memory deficits, evolving towards a confusional state leading to dementia and finally death. Mean age at onset is 50 years and typical disease duration is between 7 and 36 months, with a mean duration of 18 months. ${ }^{3}$

The disease is associated with a point mutation in the 178 codon of the prion protein $(\mathrm{PrP})$ gene (PRNP) with a substitution of asparagine for aspartic (PrP 178Asn) associated with methionine (Met) in the naturally polymorphic codon 129 of the mutated PRNP. $^{45}$ Additionally the polymorphic codon 129 in the non-mutated allele conditions the severity type: 129 Met in cases of fatal familial insomnia is associated with short term disease and more thalamic damage with fewer cortical alterations, whereas heterocigosity Met/Val in the codon 129 is associated with a more prolonged disease and widespread neuropathological damage with cortical spongiosis. ${ }^{6}$

Neuropathology discloses selective atrophy of the thalamus, the mediodorsal and anterior ventral group being especially affected. The inferior olive is also affected and isolated foci of spongiosis are found in the cortex. The affected areas show neuronal loss and astrocytic proliferation but deposits of immunoreactive PrP are not always found as in other prionic diseases. When described, immunoreactive PrP appears in discrete zones and in small amounts. ${ }^{7-9}$

Recently, six sporadic patients phenotypically similar to fatal familial insomnia but without family history and no mutations in $\mathrm{PrP}$ have been described. ${ }^{10} 11$ These share clinical and neuropathological manifestations and similar structural characteristics of $\operatorname{PrP}$ with those of fatal familial insomnia. Some authors have questioned whether fatal familial insomnia, thalamic selective degenerations, and thalamic Creutzfeldt-Jakob disease (CJD) may represent related conditions. ${ }^{12}$

\section{Patients and methods}

A Spanish family from the province of Segovia had three affected members (fig 1). In patient II.4 clinical information was retrospectively obtained. Patients III. 2 and III. 4 were seen by us and full clinical and neuropathological information was available and genetic studies could be performed.

Brains of patients III.2 and III.4 were extracted in the first 16 hours after death, embedded in $10 \%$ buffered formalin for 1 month, and then sectioned into blocks. For routine histological examination, haematoxylin-eosin, Nissl stain, Luxol fast blue, Bielschowsky silver technique, and immunohistochemical stains for glial fibrillar acidic protein (GFAP) were applied; additionally antiPrP was assayed in isolated blocks of tissue. For patient II.4 only a copy of the neuropathological report of the brain biopsy could be obtained.

DNA was obtained from leucocytes and brain tissue and the prion protein open reading frame (864 bp) was amplified by the polymerase chain reaction (PCR) as described elsewhere. ${ }^{13}$ The restriction endonuclease Tth 


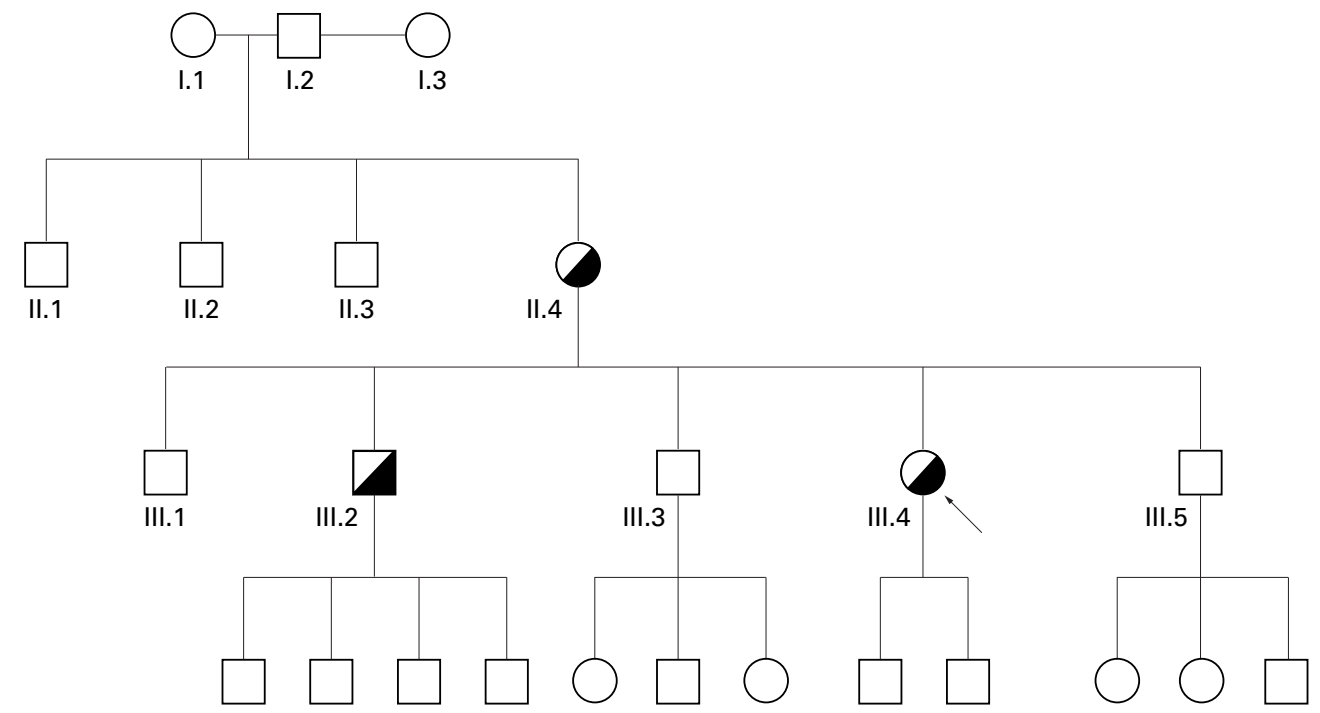

Figure 1 Family tree of the Spanish family. Hatched figures are affected members.

111 I was used for detection of the D178N mutation and the polymorphism at codon 129 was analysed by digestion with NspI.

\section{Results \\ CLINICAL DESCRIPTIONS \\ Patient II. 4}

This 47 year old woman's initial complaints were amenorrhea and insomnia, in February 1974. Two months later her family reported short term memory loss, behavioural disturbances, and hypoacusia and she was admitted to another hospital. Unspecified visual complaints, headaches, non-productive cough, and low grade fever were recorded on admission. Positive neurological findings on examination were small and sluggishly reacting pupils, fine distal tremor, and myoclonus. Hypoacusia was not demonstrated. No formal mental testing was performed. Fever and sweating were recorded. General status deteriorated after admission and the patient was admitted to the intensive care unit requiring mechanical ventilation because of ineffective cough and expectoration although no specific diagnosis was given. The clinical situation apparently deteriorated and a tracheotomy was performed. The patient was discharged with a diagnosis of CJD and died 5 months after onset. During her hospital stay four vessel angiography, neumoencephalography, EMG, and CSF analyses were performed, all being normal. An EEG showed at first left temporal slowing and in subsequent studies generalised slowing without specific findings. A right frontal cerebral biopsy was reported as non-diagnostic: normal cortical structure was found and sparse spongiosis and astrogliosis appeared in the white matter.

Patient III. 4

This 40 year old woman was seen in December 1994 for amenorrhea. Soon afterwards social withdrawal and insomnia appeared. In April 1995 she became forgetful and consulted a psychiatrist; anxiolytic and antidepressant treatment were started. One month later she was examined by us after complaining of visual blurring and diplopia without objective findings on examination. In June 1995, after a short psychiatric evaluation, the patient was again referred to us.

On admission she was anxious and collaborative but feared that she might have the same disease as her mother. Her main complaints were difficulty in breathing, visual blurring, and intense fear. General neurological examination was normal except for the absence of light response in the left pupil with normal accommodation. She scored 30/30 in the mini mental state examination. In the Wechsler adult intelligence scale she reached a verbal IQ of 84, performance of 63, and a total IQ of 72 . The examiner pointed out that the patient had great difficulties in maintaining attention. Insomnia was confirmed and was resistant to medical treatment. Episodes of profuse sweating, midriasis, and agitation of short duration and low grade fever were also noted. Blood pressure was normal. Irregular breathing and episodes of apnoea appeared including on one occasion prolonged respiratory arrest while on low doses of benzodiazepines that reverted with flumacenil. Flumacenil produced a dramatic alerting reaction in this instance and in a second infusion another day.

The patient rapidly deteriorated and when examined 20 days before death she was mute and needed help in walking. No formal mental examination could be performed but she smiled at familiar people and kept visual contact. No myoclonus was seen. There was intense weight loss. Death occurred after a pneumonia 10 months after onset

Blood tests and CSF examination were normal. 14-3-3 protein in CSF was not determined. Plasma follicle stimulating hormone and luteinising hormone concentrations were below normal (4.5 and $0.3 \mathrm{IU} / \mathrm{l})$. Initially an EEG showed left temporal focal slowing and on repeated examinations generalised bursts of slow waves could be seen. No periodic activity was detected. Neuroimaging studies (cranial CT and MRI) were normal. 
Patient III. 2

In August 1997 this 48 year old man began to display behavioural changes with disordered personality, eccentricity, and social withdrawal. He was admitted 3 months later and found to be confused, restless, and with a short term memory deficit. There were miotic pupils, hyperhidrosis, and unsteady gait. Over the subsequent weeks he became agitated, required mechanical restraint, and developed episodic "dreamy states" in which he behaved as if he was experiencing hallucinations. He deteriorated rapidly with weight loss, and finally died from an infectious nosocomial disease 7 months after onset. Insomnia was not a complaint but a disordered circadian rhythm was clear in a state of subwakefulness.

A test for 14-3-3 protein in CSF was negative. Neuroimaging (cranial CT and MRI) was normal. A brain SPECT showed non-specific global hypoperfusion. Basal EEG showed progressive diffuse slowing. Polysomnographic recording disclosed absence of sleep spindles and $\mathrm{K}$ complexes with reduced total sleep time in which only slow activity appeared and desynchronisation without rapid eye movements. No fast rhythms appeared when on treatment with benzodiazepines.

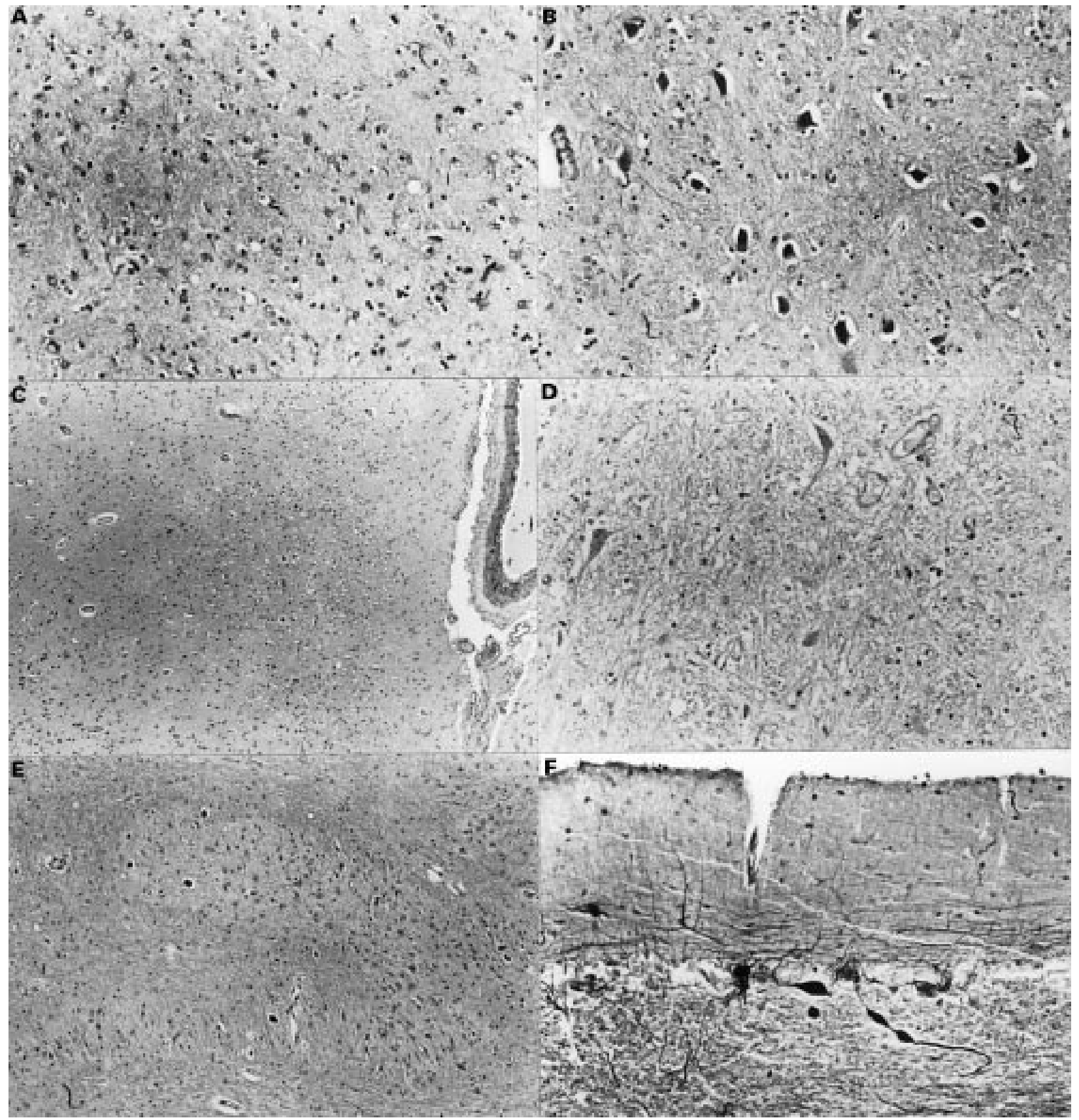

Figure 2 Neuropathological examination of case III.4: (A) medial thalamic nucleus with total neuronal loss; neuronal population is replaced by astrogliosis (haematoxylin and eosin $\times 200$ ). (B) Relative preservation of the neuronal population in the lateral nucleus (haematoxylin and eosin $\times 200$ ). (C) Parietal cortex, with spongiosis in layer II; cortical surface is on the left (haematoxylin and eosin $\times 40$ ). (D) Central and gigantocellular bulbar reticular nucleus showing neuronal loss and astrogliosis; only three shrunken neurons can be seen (haematoxylin and eosin $\times 200$ ). (E) Lateral portion of the dorsal lamina of the olivary nucleus, with neuronal loss and astrogliosis (haematoxylin and eosin $\times 100$ ). (F) Cerebellar cortex with "torpedoes" in the Purkinje cell axons (Bielschowsky silver stain $\times 200$ ). 
NEUROPATHOLOGICAL EXAMINATIONS

In patient III.4 macroscopically there was only shrinkage of the thalamus. Microscopic examination showed severe neuronal loss and astrogliosis in the thalamus, especially in the medial, anterior, and reticular nuclei (fig $2 \mathrm{~A}$ ). The lateral nuclei were well preserved (fig $2 \mathrm{~B}$ ). The hypothalamic area was normal. The cortex appeared normal, except for a small isolated zone of spongiosis in the second layer of the parietal cortex (fig $2 \mathrm{C}$ ). There was also neuronal loss in bulbar reticular central and gigantocellular nuclei (fig $2 \mathrm{D}$ ) and in the lower olive especially in the dorsal and accessory dorsal lamina (fig $2 \mathrm{E}$ ). In the cerebellum only minimal neuronal loss in the dentate nucleus and sparse "torpedoes" in Purkinje cell axons were found (fig $2 \mathrm{~F}$ ). Immunohistochemistry was negative for deposits of $\operatorname{PrP}$.

The brain of patient III.2 showed no significant macroscopical findings. Neuronal loss and astrogliosis were found in the thalamus, especially in the ventral anterior, medial dorsal, and pulvinar nuclei. This was also a feature of the inferior olive. In the cerebellum, Purkinje cell "torpedoes" and astrogliosis were found, with neuronal loss in the dentate nucleus. A focus of spongiosis and astrogliosis was found bilaterally in the temporal cortex. The immunohistochemistry of discrete zones was negative for PrP deposits. Western blotting was not performed.

GENETIC STUDIES

DNA was obtained from peripheral blood leucocytes (patient III.2) and from formalin fixed brain tissue (patient III.4). Both patients harboured the PrP 178Asn mutation and were also homozygous for Met in the 129 codon.

\section{Discussion}

The clinicopathological phenotype here reported is the classic clinical fatal familial insomnia presentation with short term evolution, insomnia, and severe thalamic pathology in relation to the state of Met homocigosity in the codon $129 .{ }^{6}$ Both female patients had amenorrhea as their initial isolated symptom, a feature not previously described. The low gonadotropin concentrations in patient III.4, also found in the original report of fatal familial insomnia, ${ }^{1}$ are consistent with an early hypothalamic dysfunction.

Other unusual clinical features are the respiratory problems of patient III.4: dyspnoea and tachipnoea evolving into irregular breathing with phases of apnoea. Patient II.4 was connected to a mechanical ventilator for 7 days without a known specific diagnosis. Respiratory complaints have been reported in other patients with fatal familial insomnia. The propositus of the original Italian family with fatal familial insomnia developed breathing irregularities with apnoea and a dramatic alerting reaction with flumacenil similar to that of our patient. ${ }^{1}$ Episodes of apnoea were also reported in a French family (patient III-4, family I) and another French patient had irregular breathing (patient II-3, family 2). ${ }^{14}$ Sleep apnoea was suspected in patient 9 of the German CJD surveil- lance study. ${ }^{9}$ Austrian patients IV-5 and III-5 complained of dyspnoea and irregular breathing and inspiratory stridor was noted. ${ }^{7}$ Patient V-14 of the McK family experienced recurrent respiratory distress. ${ }^{15}$ The Japanese patient reported also experienced tachipnoea. ${ }^{16}$ The patient of the WG family had inspiratory stridor and apnoea because of inspiratory adduction of the vocal cords. ${ }^{17}$

We have no definite hypothesis to explain the respiratory disturbances but they could be related to pathology of the bulbar reticular nuclei as found in our patient III.4. The brain stem is not usually affected in fatal familial insomnia except for changes due to degeneration of the inferior olivary nuclei. However, in a recent report of an Austrian family with an exhaustive neuropathological examination, ${ }^{7}$ brainstem pathology was consistent, widespread, and conspicuous: the reticular nuclei were the most affected at the level of the medulla and pons. All patients reported with respiratory disturbances have an average survival time of 11 months. In all of these patients in whom genotype was available it was homozygous for Met in the 129 codon. We think that one of the reasons for a shorter course in this group of patients could be complications due to respiratory dysfunction.

In our opinion this prion disease can nowadays be suspected clinically, especially in its short term variant, and molecular studies are a vital aid in supporting the diagnosis.

1 Lugaresi E, Medori R, Montagna P, et al. Fatal familial insomnia and dysautonomia with selective degeneration of halamic nuclei. N Engl F Med 1986;315:997-1003.

2 Gallassi R, Morreale A, Montagna P, et al. Fatal familial insomnia: behavioral and cognitive features. Neurology 1996;46:935-9

3 Gambetti P, Parchi P, Petersen RB, et al. Fatal familial insomnia and familial Creutzfeldt-Jakob disease: clinical, pathological and molecular features. Brain Pathol 1995;5: 43-51.

4 Goldfarb LG, Haltia M, Brown P, et al. New mutation in scrapie amyloid precursor gene (at codon 178) in Finnish Creutzfeldt-Jakob kindred. Lancet 1991;337:425.

5 Medori R, Tritschler HJ, LeBlanc A, et al. Fatal familial insomnia, a prion disease with a mutation at codon 178 of the prion protein gene. $N$ Engl $f$ Med 1992;326:444-9.

6 Montagna P, Cortelli P, Avoni P, et al. Clinical features of fatal familial insomnia: phenotypic variability in relation to a polymorphism at codon 129 of the prion protein gene. Brain Pathol 1998;8:515-20.

7 Almer G, Hainfellner JA, Brücke $\mathrm{T}$ et al. Fatal familial insomnia: a new Austrian family. Brain 1999;122:5-16.

8 McLean CA, Storey E, Gardner RJM, et al. The D178N (cis-129M) "fatal familial insomnia" mutation associated with diverse clinicopathological phenotypes in an Australian kindred. Neurology 1997;49:552-8.

9 Zerr I, Giese A, Windl O, et al. Phenotypic variability in fatal familial insomnia (D178N-129M) genotype. Neurology 1998;51:1398-405.

10 Mastrianni JA, Nixon R, Layzer R, et al. Prion protein conformation in a patient with sporadic fatal insomnia. $N$ Engl f Med 1999;340:1630-8.

11 Parchi P, Capellari S, Chin S, et al. A subtype of sporadic prion disease mimicking fatal familial insomnia. Neurology prion disease mim

12 Gambetti P, Lugaresi E. Conclusions of the symposium. Brain Pathol 1998;8:571-5.

13 Cuadrado N, Ruiz-Bremon A, Gonzalo Y, et al. Diagnóstico de las encefalopatías espongiformes transmisibles en España desde una perspectiva poblacional. Neurologia 1999;14:429-36.

14 Julien J, Vital C, Delisle MB, et al. The French FFI cases. Brain Pathol 1998;8:555-8.

15 Little BW, Brown PW, Rodgers-Johnson P, et al. Familial myoclonic dementia masquerading as Creutzfeldt-Jakob disease. Ann Neurol 1986;20:231-9.

16 Nagayama $M$, Shinohara Y, Furukawa $H$, et al. Fatal familial insomnia with a mutation at codon 178 of the prion protein gene: first report from Japan. Neurology 1996;47: protein gene.

17 Reder AT, Mednick AS, Brown P, et al Clinical and genetic studies of fatal familial insomnia. Neurology 1995;45:106875 . 